\title{
Interpersonal Forgiveness and Meaning in Life in Older Adults: The Mediating and Moderating Roles of the Religious Meaning System
}

\author{
Dariusz Krok ${ }^{1, *(D)}$ and Beata Zarzycka ${ }^{2}$ (D) \\ 1 Department of Health and Quality of Life Psychology, Institute of Psychology, University of Opole, \\ 45-040 Opole, Poland \\ 2 Department of Social Psychology and Psychology of Religion, Institute of Psychology, \\ Faculty of Social Sciences, John Paul II Catholic University of Lublin, 20-950 Lublin, Poland; \\ zarzycka@kul.lublin.pl \\ * Correspondence: dkrok@uni.opole.pl
}

Citation: Krok, Dariusz, and Beata Zarzycka. 2021. Interpersonal

Forgiveness and Meaning in Life in Older Adults: The Mediating and Moderating Roles of the Religious Meaning System. Religions 12: 37. https: / / doi.org/10.3390/rel12010037

Received: 27 November 2020

Accepted: 6 January 2021

Published: 7 January 2021

Publisher's Note: MDPI stays neutral with regard to jurisdictional clai$\mathrm{ms}$ in published maps and institutional affiliations.

Copyright: (C) 2021 by the authors. Licensee MDPI, Basel, Switzerland. This article is an open access article distributed under the terms and conditions of the Creative Commons Attribution (CC BY) license (https:// creativecommons.org/licenses/by/ $4.0 /)$.

\begin{abstract}
Forgiving others may play an important role in achieving meaning in life as it offers a valuable platform for deliberate moral acts of acceptance of positive affect, behaviour, and cognition towards a transgressor. The aim of this paper was to analyse the relationship between forgiveness and presence, and the search for meaning in life, as well as the mediating role of the religious meaning system in this relationship among older adults. A total of 205 older adults, 112 women and 93 men, participated in the study. The mean age was 72.59. The Transgression-Related Interpersonal Motivations Scale, the Meaning in Life Questionnaire, and the Religious Meaning System Questionnaire were employed in the research; revenge and avoidance revealed negative correlations with presence, whereas benevolence showed positive correlations, but not with the search for meaning in life. The religious meaning system was confirmed as a mediator in the relationships between forgiveness (revenge, avoidance, and benevolence) and both presence and the search for meaning. The findings point to the significant role played by religious beliefs and behaviour in the domain of purpose and goals. Additionally, testing the mediation and moderation effects sheds new light on the interaction of compassion- and goal-oriented mechanisms in older adults' meaning in life.
\end{abstract}

Keywords: forgiveness; revenge; avoidance; benevolence; religious meaning; meaning in life; presence of meaning; search for meaning

\section{Introduction}

The study of forgiveness has flourished since scientists discovered its benefits for physical and mental health. When defining forgiveness, scholars focus on the tendency to let go of negative thoughts, feelings, and behaviours towards an offender (for a review of definitions, see Worthington 2005). For example, Enright et al. (1998, pp. 46-47) defined forgiveness in terms of "a willingness to abandon one's right to resentment, negative judgment, and indifferent behavior toward one who unjustly injured us, while fostering the undeserved qualities of compassion, generosity, and even love toward him or her". Fitzgibbons (1986, pp. 629-30) emphasised "releasing the person who caused an injury from potential retaliation". In the present article, we focus primarily on state forgiveness, which is one's degree of forgiveness of a specific offense. McCullough et al. (2007, p. 491) defined forgiveness as "a suite of prosocial changes in one's motivations toward an interpersonal transgressor". These prosocial changes in motivations are a complex of emotional, cognitive, and behavioural phenomena, in which the negative affect, desire for revenge, and avoidance tendencies towards the wrongdoer are diminished (McCullough et al. 2001). Thus, McCullough indicated three aspects of motivations associated with forgiveness: revenge, avoidance, and benevolence (McCullough et al. 1998). All the definitions presented 
above are based on the assumption that forgiveness is a conscious, deliberate, and moral act of acceptance of positive affect, behaviour, and cognition towards a transgressor or life experience in the face of an acknowledged injustice (Van Dyke and Elias 2007).

A large number of studies have examined the benefits of forgiveness to mental health and wellbeing (Toussaint et al. 2015). Forgiveness has been confirmed to positively correlate with global mental health (Davis et al. 2015), existential and religious wellbeing (Rye et al. 2000), life satisfaction (Thompson et al. 2005), as well as negatively with depression (Brown 2003), anger, and anxiety (Lawler-Row and Piferi 2006). Vice versa, difficulty forgiving others, oneself, or God is positively correlated with depression and anxiety (Exline et al. 1999; Maltby et al. 2001). Forgiving others may also play an important role in achieving meaning in life (Frankl 1962), since it can provide the ability to change a person's viewpoint regarding different situations, change judgments about those involved, and develop greater perspective-taking capability (Toussaint et al. 2017). Research has demonstrated that there are different forms of forgiveness: dispositional forgiveness and the degree of forgiveness (Van Tongeren et al. 2015), forgiveness of oneself, forgiveness of others, and a sense of forgiveness by God (Głaz 2019) were positively related to meaning in life among university students. However, fewer studies have examined the relationship between forgiveness and meaning in life in older adults (Derdaele et al. 2019). Nevertheless, in late life, forgiveness can play an important role, because a shift in focus has been observed from a self-centred to a more altruistic perspective over the course of a life (Tornstam 2005).

Meaning in life encompasses a wide range of human experiences related to purpose and significance and is defined as "the extent to which people comprehend, make sense of, or see significance in their lives, accompanied by the degree to which they perceive themselves to have purpose, mission, or overarching aim in life" (Steger 2009, p. 682). Two principal dimensions can be distinguished in people's approach to understanding meaning in life: presence and search (Steger et al. 2006). The former reflects the degree to which a person perceives their life as significant and meaningful, whereas the latter represents the degree to which people are involved in a search for meaning in life. The forgiveness process can enhance people's overall sense of meaning in life, because it helps people to discover a deeper meaning in transgression, a new sense of compassion for others, and an enhanced gratitude for interpersonal support (Van Dyke and Elias 2007). For this reason, we believe that forgiveness can be related to people's actual presence of meaning in life. The search for meaning in life seems to be a more complex variable, which makes it difficult to make a precise prediction about the relationship between forgiveness and search for meaning. By definition, search for meaning indicates people's efforts to find the meaning of life, but it also indirectly suggests a lack of present meaning (Steger et al. 2008). For this reason, we have formulated an exploratory hypothesis about the relationship between forgiveness and search for meaning without specifying the direction of this relationship; it is included in Hypothesis 1. Based on these assumptions, we hypothesised:

Hypothesis 1. Forgiveness correlates with the presence of meaning in life; specifically, benevolence correlates positively with meaning in life, whereas revenge and avoidance correlate negatively with meaning in life; forgiveness also correlates with the search for meaning in life.

How can forgiveness enhance meaning in life? We suppose that the religious meaning system can explain the mechanism of the relationship between forgiveness and the sense of meaning in life. The relationship between forgiveness and religiosity has been widely studied, which is well reflected in bibliographic databases. On PsycINFO, we found 345 empirical articles in peer-reviewed journals, published between 2000 and 2020, with forgiveness and religion as keywords (9 November 2020). Most studies have consistently confirmed a positive relationship between forgiveness and religion, specifically with trait forgiveness and attitudes towards forgiveness (Macaskill 2007; Witvliet et al. 2008). These findings suggest that religious or spiritual individuals view themselves as forgiving or think they should forgive (Davis et al. 2012; Zarzycka 2019). In other words, religiosity may 
predispose people to engage in forgiveness-oriented activities. This is not surprising, since forgiveness is an important element of religious doctrines within main religious traditions, namely Judaism, Christianity, and Islam. Christianity goes even further, proclaiming unconditional forgiveness even if there is no repentance on the wrongdoer's side (Peterson and Seligman 2004).

Most previous studies, although they employed correlational design, analysed religion as a predictor of forgiveness. These studies, typically based on a substantive approach while operationalising religion, focused on individuals' religious beliefs, behaviours, or other individual traits. The other, functional approach focusses on how religion operates within an individual's lives (Hill and Edwards 2013), and one of the main functions of religion is to provide a source of meaning. Hood et al. (2009) emphasised comprehensiveness, accessibility, transcendence, and direct claims as unique criteria by which religion is capable of providing meaning. Religion is the most comprehensive of all meaning systems, since it includes an extensive range of other sources of meaning, for instance, values, family, and social relationships. Religion can be accessible to people through religious doctrines, education, and ethical norms. In religion, people search for an invisible reality and explore "ultimate concerns", where they can find higher meaning. Finally, religion facilitates people's efforts to interpret their experiences in terms of existential or sacred meanings (Krok 2015). Thus, religion can be framed as a meaning system which can help individuals to comprehend their lives and the world and consequently enable them to discover purpose and meaning in their lives.

The conceptualisation of religiousness in terms of the religious meaning system is based on the view that religion can help individuals to explain reality in terms of significance and purpose (Emmons 2005; Park 2005). The religious meaning system is defined as an idiosyncratic system of concepts related to the sacred and having references to self, other people, and the world (Krok 2014). The religious meaning system encompasses two dimensions: (1) an orientation that evaluates the extent to which religion can help individuals to comprehend their lives and the world and (2) meaningfulness that represents the ability of religion to enable individuals to discover purpose and meaning in their lives. As Park (2005) observed, for many people, religion is an important philosophical orientation that serves as an individual's schema, informing beliefs about the self and the world which provides understanding of both mundane and extraordinary events. The role of religion can be especially important when people address existential questions in the context of difficult moments. Research has demonstrated that in stressful situations, people often rely on their meaning systems which provide orientation and significance (Park 2013). Religious meaning systems can also be an important issue in the context of forgiveness. We think that there are two ways in which religious meaning systems can mediate or moderate the relationship between people's motivations towards an interpersonal transgressor and their meaning in life. First, forgiveness is a common component of religiousness and people who are forgiving may also be likely to search for religious understanding or meaning for why they are engaging in the act of forgiving (religious meaning system). As the act of forgiveness stimulates a religious search for meaning, this mechanism then may also relate to greater meaning. Thus, a mediation model can help to explain the underlying activity of the religious meaning system in the relationship between forgiveness and meaning in life (Figure 1). Based on these assumptions, we hypothesised:

Hypothesis 2. The religious meaning system is a mediator in the relationship between forgiveness and presence and the search for meaning in life. 


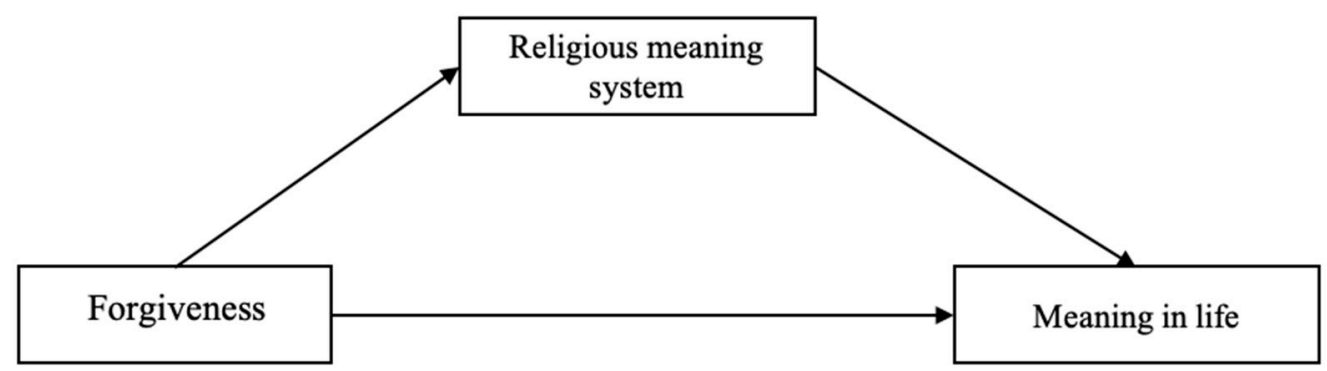

Figure 1. A conceptual model of the mediating role of the religious meaning system in the relationship between forgiveness and meaning in life.

Next, the religious meaning system can also moderate the relationship between forgiveness and meaning in life. Theoretical assumptions and empirical findings (Huber and Huber 2012) provided support for the claim that the religiosity status can affect the way in which various religious contents relate to people's psychological functioning (Zarzycka et al. 2020). For example, based on the personal construct theory, Huber (2007) claimed that when the religious construct is salient in the personal construct system, it has a much stronger relevance for general psychological dispositions than when it is placed in a subordinate or a marginal position. This proposition was confirmed with regard to the political relevance of religious concepts (Huber 2008) and in relation to the social relevance of the experience of forgiveness by God (Huber et al. 2011). Thus, as most religious traditions value interpersonal forgiveness, the high importance of the religious meaning system may enhance the positive effect of forgiveness on meaning in life. We then decided to examine whether the religious meaning system could function as a cognitive restructuring factor and moderate the association between forgiveness understood in terms of a prosocial change in a person's thoughts, emotions, and behaviours, and meaning in life. Available research suggests that forgiveness can be partially determined by the level of religiosity (Laufer et al. 2009). Religiosity has also consistently been related to meaning in life in various age groups, enabling individuals to pursue important striving and goals and to find significance in their lives (Krok 2014; Martos et al. 2010). In addition, religiosity moderated the relationship between religious and non-religious forgiveness (Huber et al. 2011) and the relationship between distress and growth (Laufer et al. 2009). Therefore, it is important to explain the potential effects of different dimensions of forgiveness to reveal specific moderating contributions of the religious meaning system to experiencing meaning in life. Thus, a moderation model can help to explain how the relationship between forgiveness and meaning in life changes on various levels of the religious meaning system (Figure 2).

Based on these assumptions, we hypothesized:

Hypothesis 3 . The religious meaning system is a moderator in the relationship between forgiveness and presence and the search for meaning in life.

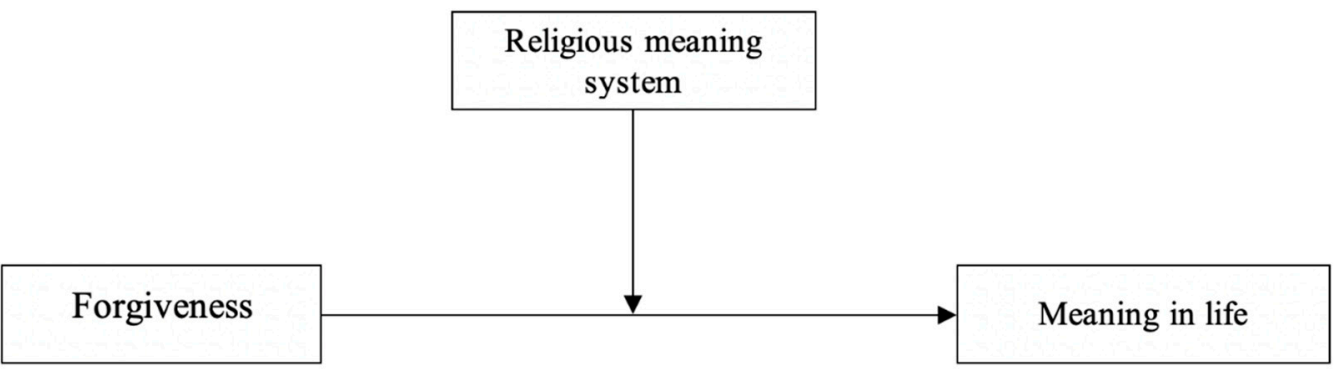

Figure 2. A conceptual model of the moderating role of the religious meaning system in the relationship between forgiveness and meaning in life.

Our study may extend previous research in two important ways. First, most previous studies employed various measures of religiousness, e.g., individuals' religious motivation, 
beliefs, behaviours, or other individual actions (Huber et al. 2011; Laufer et al. 2009) which represent a substantive approach to studying religiousness. Therefore, in many studies, religiousness was analysed as a potential predictor of forgiveness. The religious meaning system, which is defined as a cognitive system allowing people to interpret life events from a religious perspective, indicates how religiousness operates in individuals' lives and thus represents a functional approach to studying religiousness (Hill and Edwards 2013). Our research allows us to grasp the meaning-oriented role of religiousness in the relationship between interpersonal forgiveness and meaning in life. Second, late adulthood is associated with a stronger focus on religious issues and, according to Erikson's (1959) concept of development, it is associated with the need for summaries and a deep reflection on what has happened in one's entire life. Therefore, an analysis of the religious meaning making among older adults can provide particularly important knowledge about these processes.

\section{Materials and Methods}

\subsection{Participants and Procedure}

A total of 205 older adults (112 women and 93 men), aged between 60 and 92, participated in the current study. The mean age was $72.59(\mathrm{SD}=6.85)$. All the participants were Caucasians who formed a representative sample of Polish older adults in terms of gender, age, and social position. Most participants were Christians (85.4\% Catholic, 8.3\% Protestant), with the remaining $6.3 \%$ characterising themselves as non-believers. The sample represented characteristic social features of the Polish population, which is predominately Christian. Participants were randomly recruited via personal contact, social and cultural organisations, and care homes with the aim of covering all social strata of Polish society. Participants were invited to complete a set of questionnaires and then return them either personally to research assistants or by post. No time limitations were imposed on the participants. After the study, participants were fully debriefed, and their queries were explained by the researcher. The study was anonymous, and its conditions were approved by the University Ethics Committee.

\subsection{Measures}

\subsubsection{Transgression-Related Interpersonal Motivations Scale (TRIM)}

The TRIM scale is an 18-item instrument that measures interpersonal forgiveness as a prosocial transformation of the relation towards transgressors (McCullough et al. 1998). It consists of three subscales representing types of motivations associated with forgiveness: (1) revenge motivation (e.g., I wish that something bad would happen to them; I want to see them hurt and miserable), (2) avoidance motivation (e.g., I am trying to keep as much distance between us as possible; I am living as if they don't exist, aren't around), and (3) benevolence motivation (e.g., Even though their actions hurt me, I have goodwill for them; I have given up my hurt and resentment). Items are rated on a 5-point Likert scale, from 1 (strongly disagree) to 7 (strongly agree). The scale was adapted into Polish by Kossakowska et al. (2014). The internal consistency coefficients for the current study were 0.87 (revenge motivation), 0.84 (avoidance motivation), and 0.88 (benevolence motivation).

\subsubsection{The Meaning in Life Questionnaire (MLQ)}

The MLQ was used to measure two dimensions of meaning in life (Steger et al. 2006): (1) presence (e.g., I have a good sense of what makes my life meaningful; I have discovered a satisfying life purpose) and (2) search (e.g., I am always looking to find my life's purpose; I am seeking a purpose or mission for my life). Within the framework of this questionnaire, meaning in life was defined as "the sense made of, and significance felt regarding, the nature of one's being and existence" (Steger et al. 2006, p. 81). The questionnaire comprises 10 items which are assessed on a 7-point scale ranging from 1 (absolutely untrue) to 7 (absolutely true). The internal consistency coefficients for the present study were 0.91 (presence) and 0.92 (search). 


\subsubsection{The Religious Meaning System Questionnaire (RMS)}

The RMS is a 20-item instrument that consists of two subscales measuring religiosity understood in terms of meaning systems (Krok 2014): (1) orientation (e.g., Thinking about my life, I take into account religious norms; I like watching or listening to programmes concerning religion) and (2) meaningfulness (e.g., I think that religion helps me in finding purpose in life; the question of whether God exists does not matter for me [reversed]). The religious meaning system is conceptualised as a cognitive and motivational system that allows people to understand and interpret life events and the surrounding world through the lens of significance and purpose (Krok 2009). Each subscale contains 10 items which are rated on a 7-point Likert scale, from 1 (very strongly disagree) to 7 (very strongly agree). Their sum gives a total score. The questionnaire has good psychometric qualities; criterion validity ranges from 0.77 to 0.80 (Krok 2009), and the internal consistency coefficients for the current study were 0.91 (orientation), 0.85 (meaningfulness), and 0.89 (total score).

\subsection{Statistical Methods}

The design of the current study was cross-sectional. First, we calculated descriptive statistics (means, standard deviations, and alpha reliabilities) for all the variables. Second, correlational analyses were performed to explore relationships among interpersonal forgiveness, meaning in life, and the religious meaning system. Third, to examine whether the religious meaning system mediates the relationship between interpersonal forgiveness and meaning in life, regression-based mediation analyses were conducted on a basis of the procedures advocated by Hayes (2018). Finally, moderation analyses were used to assess the moderating effects of the religious meaning system on the relationship between interpersonal forgiveness and meaning in life. Prior to the analyses, mean centring and standardising were applied for moderation analysis in order to properly estimate an interaction of interpersonal forgiveness and the religious meaning system on meaning in life. Bias-corrected confidence intervals (CI 95\%) and the bootstrapping procedure (samples $=5000)$ were used to calculate direct and indirect effects (Hayes 2018).

\section{Results}

\subsection{Preliminary Analyses Subsection}

The results of correlational calculations demonstrated that most of them turned out to be statistically significant (Table 1). Revenge and avoidance motivations were negatively related to presence of meaning and the religious meaning system. By contrast, benevolence motivation was positively related to the presence of meaning and the religious meaning system. Both the presence of meaning and the search for meaning had positive correlations with the religious meaning system. However, there were no significant correlations between all the types of motivations and search for meaning.

Table 1. Descriptive statistics and correlations among interpersonal forgiveness, meaning in life, and the religious meaning system.

\begin{tabular}{|c|c|c|c|c|c|c|c|c|}
\hline Variables & $M$ & $S D$ & 1 & 2 & 3 & 4 & 5 & 6 \\
\hline 1. Revenge motivation & 1.92 & 0.77 & - & & & & & \\
\hline 2. Avoidance motivation & 3.17 & 0.74 & $0.28 * * *$ & - & & & & \\
\hline 3. Benevolence motivation & 3.22 & 0.72 & $-0.44^{* * *}$ & $-0.51^{* * *}$ & - & & & \\
\hline 4. Presence of meaning & 5.34 & 0.96 & $-0.39 * * *$ & $-0.24^{* * *}$ & $0.26^{* * *}$ & - & & \\
\hline 5. Search for meaning & 4.34 & 1.19 & 0.08 & -0.01 & 0.13 & 0.01 & - & \\
\hline 6. Religious meaning system & 5.25 & 1.03 & $-0.55^{* * *}$ & $-0.34^{* * *}$ & $0.51 * * *$ & $0.58^{* * *}$ & $0.19 * *$ & - \\
\hline
\end{tabular}

\subsection{Mediational Analyses}

In order to examine whether the religious meaning system mediated the relationship between forgiveness and meaning in life, we conducted six mediation analyses (Model 4, Hayes 2018) in which three types of motivations (revenge, avoidance, and benevolence) 
were independent variables, while presence of meaning and search for meaning were dependent variables. The indirect effects are presented in Table 2.

Table 2. Indirect effects of forgiveness on meaning in life through the religious meaning system.

\begin{tabular}{cccc}
\hline Variables & Effect & $S E$ & [LLCI, ULCI] \\
\hline Indirect effects & & & \\
RM-RMS-PM & -0.35 & 0.05 & {$[-0.47,-0.26]$} \\
AM-RMS-PM & -0.24 & 0.04 & {$[-0.34,-0.15]$} \\
BM-RMS-PM & 0.40 & 0.06 & {$[0.28,0.53]$} \\
RM-RMS-SM & -0.28 & 0.08 & {$[-0.46,-0.14]$} \\
AM-RMS-SM & -0.11 & 0.05 & {$[-0.22,-0.03]$} \\
BM-RMS-SM & 0.13 & 0.07 & {$[0.01,0.29]$} \\
\hline
\end{tabular}

RM-revenge motivation, AM-avoidance motivation, BM-benevolence motivation, RMS—-the religious meaning system, $\mathrm{PM} —$ presence of meaning, $\mathrm{SM} —$ search for meaning.

There was a significant indirect effect of revenge motivation on presence of meaning through the religious meaning system. The regression analysis demonstrated that revenge motivation was related to the lower religious meaning system $(B=-0.73 ; p<0.001)$, which was related to a higher level of meaning in life $(B=0.47 ; p<0.001)$. A significant indirect effect occurred between avoidance motivation and presence of meaning, with the religious meaning system being a mediator. The regression analysis showed that avoidance motivation was associated with the lower religious meaning system $(B=-0.47$; $p<0.001)$, which in turn was associated with a higher level of presence of meaning $(B=0.51$; $p<0.001$ ). There was also a significant indirect effect of benevolence motivation on presence of meaning through the religious meaning system. Benevolence motivation related to the higher religious meaning system $(B=0.72 ; p<0.001)$, which in turn was related to a higher level of presence of meaning $(B=0.55 ; p<0.001)$.

As regards the search for meaning as a dependent variable, all the following indirect effects were significant with the religious meaning system being a mediator: revenge motivation on search for meaning, avoidance motivation on search for meaning, and benevolence motivation on search for meaning. The regression analysis showed that revenge motivation was associated with the lower religious meaning system $(B=-0.74$; $p<0.001)$, which in turn was associated with a higher level of search for meaning $(B=0.38$; $p<0.001)$. Next, avoidance motivation was related to the lower religious meaning system $(B=-0.47 ; p<0.001)$, which in turn was related to a higher level of search for meaning $(B=0.23 ; p<0.01)$. Finally, benevolence motivation was associated with the higher religious meaning system $(B=0.72 ; p<0.001)$, which in turn was associated with a higher level of search for meaning $(B=0.18 ; p<0.05)$.

For presence of meaning, the strongest mediation estimate was for benevolence motivation ( $\mathrm{IE}=0.40 ; 95 \% \mathrm{CI}(0.28,0.53))$, while in the case of search for meaning, the strongest mediation estimate occurred for revenge motivation (IE $=-0.28 ; 95 \% \mathrm{CI}(-0.46,-0.14)$ ).

\subsection{Moderation Analyses}

To test whether the religious meaning system moderated the relationship between interpersonal forgiveness and meaning in life, we used a set of moderation analyses. Three interactions of the six possible turned out to be significant.

The analysis revealed a significant interaction effect of revenge motivation and the religious meaning system in relation to presence of meaning $(B=-0.20 ; 95 \% \mathrm{CI}(-0.33$; $\left.-0.07), \Delta R^{2}=0.03\right)$. Revenge motivation was negatively related to presence of meaning at an average level of the religious meaning system $(B=-0.20 ; 95 \% \mathrm{CI}(-0.40 ;-0.01))$ and a high level of the religious meaning system $(B=-0.40 ; 95 \% \mathrm{CI}(-0.66 ;-0.14))$. By contrast, revenge motivation did not predict change in presence of meaning for the low religious meaning system $(B=0.01 ; 95 \% \mathrm{CI}(-0.22 ; 0.24))$. Results revealed that the effect of revenge motivation on presence of meaning was stronger at higher levels of the religious meaning system (Figure 3). 


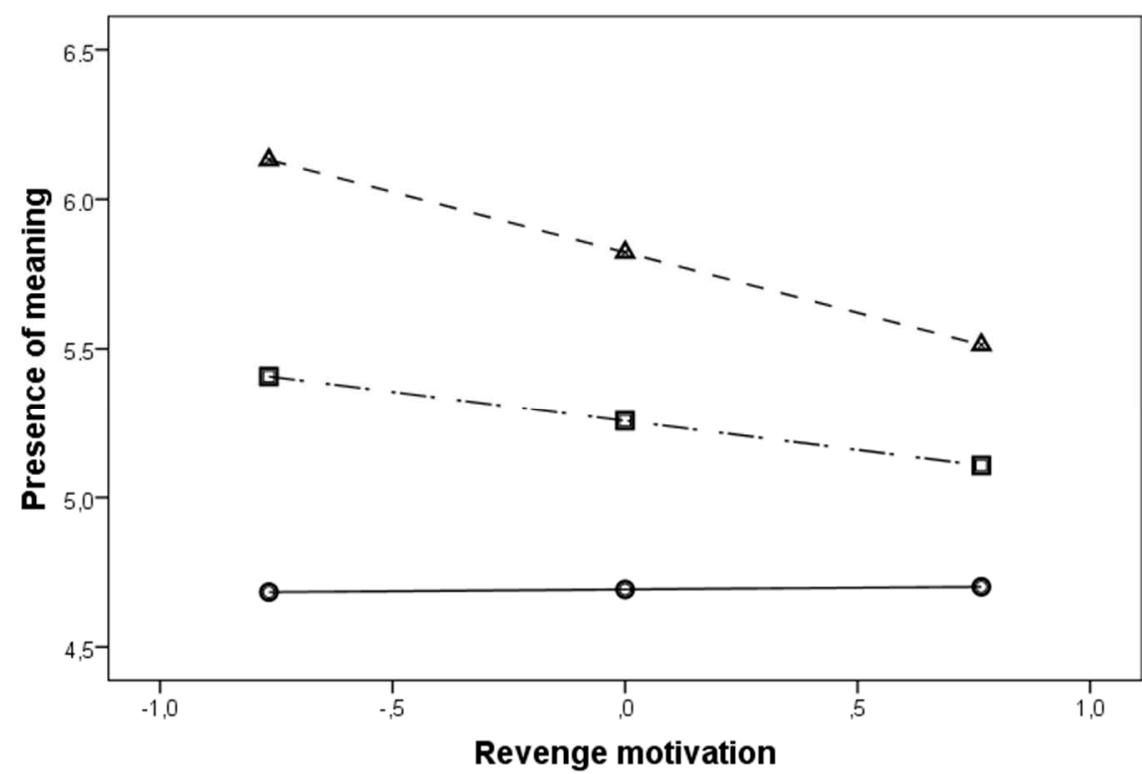

The religious meaning system

O Low

$\square$ Moderate

$\Delta$ High

Figure 3. A visual representation of the moderation of the effect of revenge motivation on presence of meaning at low $(-1 \mathrm{SD})$, moderate $(M)$, and high $(+1 \mathrm{SD})$ levels of the religious meaning system.

There was also a significant interaction effect of benevolence motivation and the religious meaning system on presence of meaning $\left(B=0.25 ; 95 \% \mathrm{CI}(0.11 ; 0.38), \Delta \mathrm{R}^{2}=0.03\right)$. Benevolence motivation was negatively related to presence of meaning at a low level of the religious meaning system $(B=-0.39 ; 95 \% \mathrm{CI}(-0.64 ;-0.13))$. By contrast, benevolence motivation did not predict change in presence of meaning for the average $(B=-0.14 ; 95 \%$ CI $(-0.31 ; 0.03))$ or high religious meaning system $(B=-0.12 ; 95 \% \mathrm{CI}(-0.06 ; 0.29))$. The effect of benevolence motivation on presence of meaning was weaker at lower levels of the religious meaning system (Figure 4).

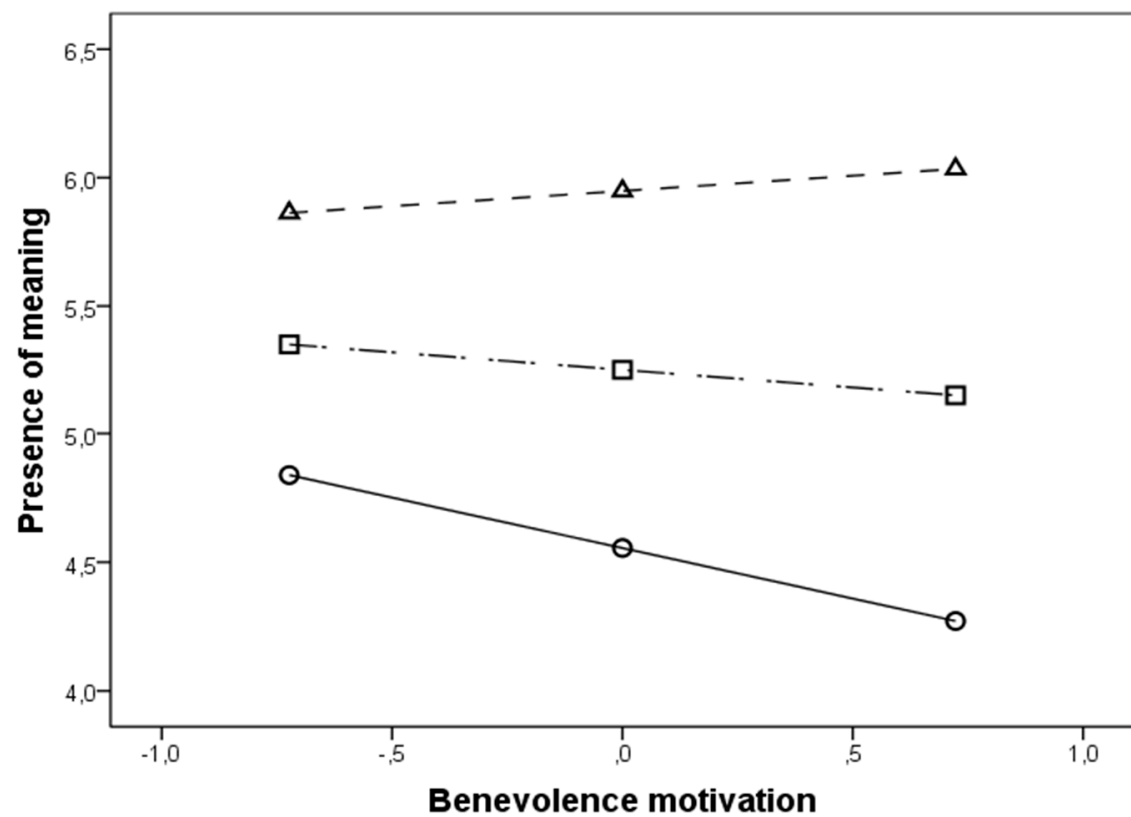

The religious meaning system

O Low

$\square$ Moderate

$\Delta$ High

Figure 4. A visual representation of the moderation of the effect of benevolence motivation on presence of meaning at low $(-1 S D)$, moderate $(\mathrm{M})$, and high (+1SD) levels of the religious meaning system.

Finally, a significant interaction effect occurred of revenge motivation and the religious meaning system on search for meaning $\left(B=0.21 ; 95 \% C I(0.01 ; 0.41), \Delta R^{2}=0.02\right)$. Revenge motivation was positively related to search for meaning at a low level of the religious 
meaning system $(B=0.26 ; 95 \% \mathrm{CI}(0.01 ; 0.51))$, an average level of the religious meaning system $(B=0.48 ; 95 \% \mathrm{CI}(0.23 ; 0.72))$, and a high level of the religious meaning system $(B=0.69 ; 95 \% \mathrm{CI}(0.31 ; 1.08))$. The effect of revenge motivation on the search for meaning was stronger at higher levels of the religious meaning system (Figure 5).

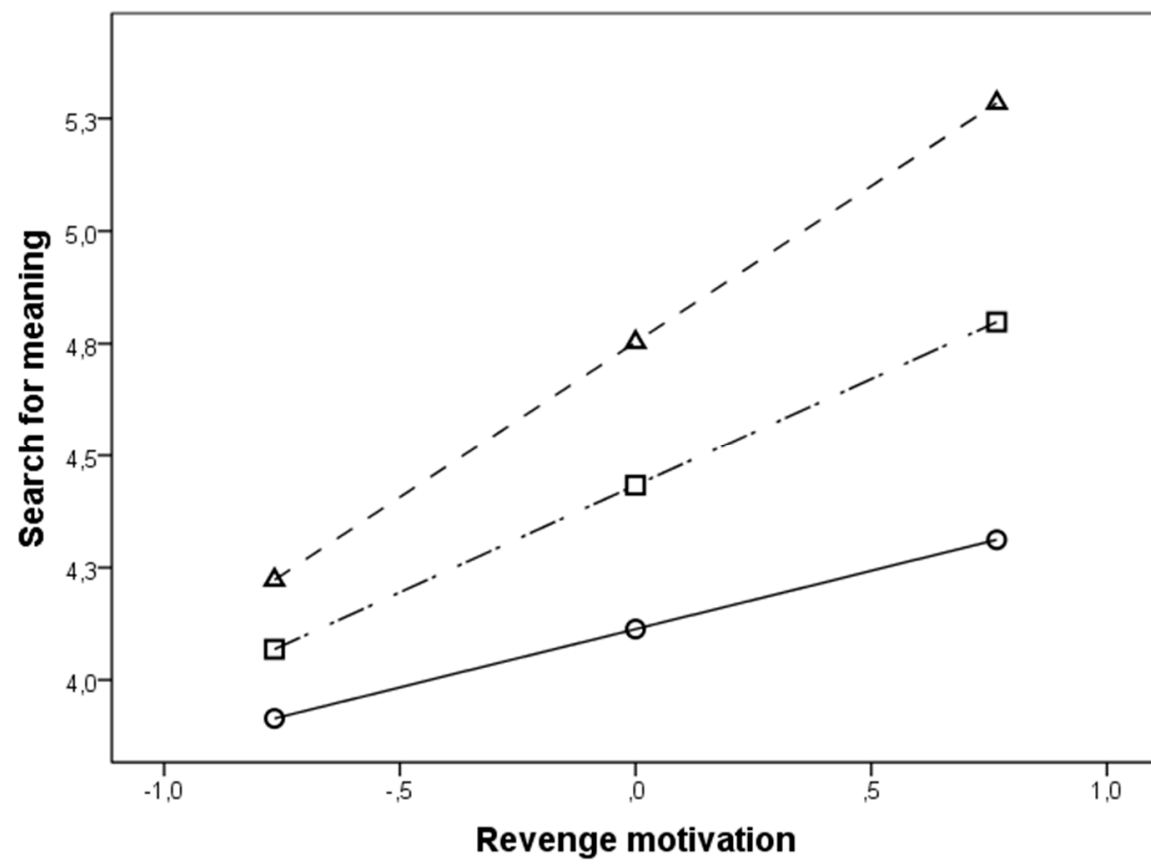

The religious meaning system O Low $\square$ Moderate $\Delta$ High

Figure 5. A visual representation of the moderation of the effect of revenge motivation on the search for meaning at low $(-1 \mathrm{SD})$, moderate $(\mathrm{M})$, and high (+1SD) levels of the religious meaning system.

Three other interactions turned out non-significant: the effect of avoidance motivation and the religious meaning system in relation to presence of meaning $(B=-0.08 ; 95 \% \mathrm{CI}$ $(-0.20 ; 0.04), p<0.17)$; the effect of avoidance motivation and the religious meaning system in relation to search for meaning $(B=0.15 ; 95 \% \mathrm{CI}(-0.08 ; 0.40), p<0.20)$, and the effect of benevolence motivation and the religious meaning system in relation to search for meaning $(B=-0.11 ; 95 \%$ CI $(-0.36 ; 0.14), p<0.36)$.

\section{Discussion}

The aim of the present study was to analyse the relationship between forgiveness and meaning in life. We also aimed to investigate whether the religious meaning system mediated or moderated the expected positive relationship between forgiveness of others and meaning in life in an elderly population. Three dimensions of forgiveness were tested as independent variables-revenge, avoidance, and benevolence-and two aspects of meaning in life were tested as dependent variables-presence and search for meaning. We expected that benevolence would show positive relationships, whereas revenge and avoidance would show negative relationships with both presence and search for meaning in life (Hypothesis 1), and we assumed that the religious meaning system would operate as a mediator (Hypothesis 2) and a moderator (Hypothesis 3) in these relationships.

With regard to our first hypothesis, we found that forgiveness was associated with presence of meaning, but not with search for meaning. In line with what we hypothesised, revenge and avoidance correlated negatively, whereas benevolence correlated positively with presence of meaning in life. Therefore, elderly individuals who were more forgiving tended to have a higher sense of meaning in their lives. Our findings support Frankl's (1962) theoretical claim that forgiveness enhances people's sense of meaning in life. This is in line with prior empirical research on the forgiveness-meaning in life relationship in student and adult samples (Głaz 2019; Toussaint et al. 2017). Our research also extends the existing 
knowledge since it shows that the dimensions of forgiveness are related to the presence of, but not to the search for meaning in life. Specifically, the lower the propensity for revenge and avoidance, and greater the benevolence, the greater the present sense of meaning in life. It seems likely that elderly people can find meaning in developing, maintaining, or restoring their social relations. Taking into account the undeniable fact that social interactions offer many psychological benefits to elderly people in terms of personal growth and purpose, it is fully understood that they try to shape them in an affirmative and friendly way; forgiving others and letting go of grudges thus leads to a more satisfactory sense of meaning and significance. Previous research confirmed that social relationships are the most consistent and compelling source of meaning ( $\mathrm{O}^{\prime}$ Donnell et al. 2014), and yet, forgiveness can be considered a tool for renewing or recovering relationships as it enables elderly people to develop compassion for others and appreciate social support systems which were harmed or broken in the past. This can be of the utmost importance to elderly people, since they perceive their time to be running out and thus prioritise emotional and relational goals (Hantman and Cohen 2010).

To our surprise, forgiveness was not associated with search for meaning. Trying to explain this result, we can draw on those specific developmental features of older adults which are related to meaning in life. According to Erikson (1959), in late adulthood, people tend to reflect back on how their life has been lived and begin to accept the kind of person they have become over the years. This can be achieved by reconciling earlier planned goals with those which have actually been accomplished. During this process, individuals are likely to rely more on already established sets of purposes and goals (i.e., the presence of meaning in life) than to engage in the pursuit of new and often uncertain goals and values (i.e., the search for meaning in life) (Krause 2004). In other words, elderly people derive a sense of significance and meaning by revisiting and reflecting more upon past experiences than pursuing new ones. Additionally, because people who search for meaning are likely to question their values and ideas about life (Steger et al. 2008), they will also be less willing to forget their resentment, negative judgments, and antagonism towards a transgressor. As a consequence, the need for forgiveness which is crucial to achieving ego integrity will not have to be connected to search for meaning. Instead, a sense of fulfilment and moral compassion is created on the basis of goals and values that already exist. Another explanation for why forgiveness did not relate to search for meaning may lie in the conceptual understanding of search for meaning, which according to Steger et al. (2008) can indicate a lack of present meaning, not necessarily involving a sense of meaning. Consequently, it is logical that forgiveness was not associated with search for meaning, but it was with presence of meaning.

Finally, although there is a well-documented discrepancy between state forgiveness and religiousness, where often there is no association found (McCullough and Worthington 1999), our study revealed that benevolence was positively correlated with the religious meaning system, while revenge and avoidance motivation were negatively correlated. This can be explained by referring to the specifics of the methods we employed in our study. Although TRIM measures state forgiveness, it captures the motivation for forgiveness. RMS, on the other hand, is not a measure of religiousness, but a measure of religious meaning making. Thus, individuals who want to strengthen the motivation for benevolence and weaken the motivation for revenge and avoidance can find justification and support in a religious cognitive framework which provides guidance and standards of this kind.

The main finding of our study revealed that the religious meaning system can operate as both a mediator and moderator in the relationship of forgiveness with meaning in life. Thus, it can help to explain a mechanism as well as the context of this process. With regard to our second hypothesis, the religious meaning system was confirmed as the mediator in the relationships of three dimensions of forgiveness with both presence and search for meaning in life. Specifically, revenge and avoidance motivation were related to lower religious meaning, whereas benevolence was related to higher religious meaning which, in turn, was positively associated with both presence and the search for meaning in life. 
The religious meaning system, since it can provide justification for why to forgive, can be considered a pathway leading from forgiveness to both enhancing and developing meaning in life (Chen et al. 2019; Toussaint et al. 2015). Thus, when people attempt to change their motivation towards their wrongdoers, thus trying to increase the motive of benevolence and reduce an inclination to revenge and avoidance, religion can provide a rationale for this, which may be related to a sense of meaning in life (Chen et al. 2019). These results further confirm that religion can provide a resourceful framework for comprehension of existential problems, among which forgiveness is one. Religion as the prime example of a belief system helps to establish ways to more deeply understand the relationship between forgiveness and meaning in life (Park 2005).

With regard to our third hypothesis, we found that the religious meaning system can operate as a moderator in the relationship between forgiveness and meaning in life. Specifically, the stronger an individual's religious meaning system, the stronger the negative relationship between revenge with the presence of and the search for meaning in life. Additionally, the stronger an individual's religious meaning system, the stronger the positive relationship between benevolence and presence of meaning in life. Thus, the religious meaning system can facilitate individuals to explain forgiveness in terms of significance and purpose and establish its connections with meaning in life. These results further support Huber's (2008) claim that the religiosity status may affect the way in which various psychological variables operate and how they affect people's psychological functioning (Zarzycka et al. 2020). These results are in line with previous studies which have consistently confirmed religiosity as a predictor of engagement in forgiveness-oriented activities (Laufer et al. 2009). Interestingly, our results reveal that while explaining the presence of meaning in life, religiosity enhances benevolence and decreases motivation towards revenge, whereas explaining the search for meaning, religiosity weakens revenge motivation. Mediation analysis results appear to have confirmed these results. Namely, while taking into account the religious meaning system as a mediator, benevolence motivation had the strongest indirect effect on presence of meaning, whereas revenge motivation had the strongest indirect effect on search for meaning. These results are very interesting as they point out that people who have a meaningful and purposeful life tend to perceive religion as a source of inspiration and help in their motivation for conciliation and goodwill embedded in their awareness of forgiveness. The results also suggest that when people are in the process of searching for meaning in life, they are more inclined to perceive in religion an encouragement to give up the tendency towards revenge. However, when their need for purpose in life is met, they perceive in religion an encouragement to transform one's own motivation into benevolence. New research is needed to further investigate these scores.

Another thing that is not entirely clear refers to the total strength of moderating effects obtained in our study. Given that three of the six tested interactions were significant and three were not, it is difficult to determine whether moderating or mediating effects are stronger. Apparently, the religious meaning system can operate as both a moderator and a mediator in the relationship between forgiveness and meaning in life in older adults. This interpretation is supported by previous studies which found that religiosity was a moderator in the relationship between distress and growth in Israeli adolescents (Laufer et al. 2009) and between religious and non-religious forgiveness (Huber et al. 2011). At the same time, religiosity was a mediator of wellbeing (Morano and King 2005) to which meaning in life is strongly related. The reason for the two-sided nature of the religious meaning system in the relationship between forgiveness and meaning in life may lie in the significant role of religion in older adults' life. Older people tend to view religious beliefs and practices as meaningful and valuable, especially in times of distress and trouble (McFadden 2013). Therefore, religiosity can provide them with values and norms which are helpful in forgiveness-oriented activities and also strengthen the impact of pro-forgiveness attitudes on meaning life.

This study is, however, subject to certain limitations. First, this was a convenience sample self-selected from a specific geographical area, and thus, the results may not be 
generalisable to the broader population. Second, this was a cross-sectional study, and causal conclusions cannot be made. Although we tested the following model: "ForgivenessReligious Meaning System-Meaning in life", it does not mean that forgiveness makes an impact on religiosity which in turn influences meaning in life as an alternative model: "Religious Meaning System-Forgiveness-Meaning in life" is also possible. Longitudinal research is thus required to establish causal relationships between forgiveness, religiosity, and meaning in life. Third, this study did not examine forgiveness in specific contexts or with potential modifying factors of the forgiveness and meaning in life associations. Fourth, all variables were self-reported, which may be subject to social desirability and common methods bias. Fifth, taking into account the lack of direct relationships between forgiveness and search for meaning, future research should investigate its potential causes, e.g., by employing more precise measures of search for meaning or examining it as a variable totally separated from presence of meaning.

Despite the above limitations, the present study compellingly confirmed the significance of examining relationships between forgiveness and meaning in life in older adults within mediation and moderation models incorporating the religious meaning system. It demonstrated that the religious meaning system mediated the relationships of three dimensions of forgiveness with both presence and search for meaning in life, which emphasised the significant role of religious beliefs and behaviour in the domain of purpose and goals. In addition, interestingly, the findings revealed that the religious meaning system operated as a moderator in the relationship between forgiveness and meaning in life. Through testing the mediation and moderation effects, this study provides new evidence on the interplay of compassion- and goal-oriented mechanisms in older adults' structures of meaning in life, which can also offer practical implications for both the elderly and their caregivers.

Author Contributions: Conceptualization, D.K. and B.Z.; methodology, D.K. and B.Z.; formal analysis, B.Z. and D.K.; investigation, D.K.; data curation, D.K.; funding acquisition, B.Z.; writing (original draft preparation), D.K. and B.Z.; writing (review and editing), B.Z. and D.K.; visualization, D.K. All authors have read and agreed to the published version of the manuscript.

Funding: This research received no external funding.

Institutional Review Board Statement: The study was conducted according to the guidelines of the Declaration of Helsinki, and approved by the Ethics Committee of the University of Opole (protocol code 6/2019, 09.05.2019).

Informed Consent Statement: Informed consent was obtained from all subjects involved in the study.

Data Availability Statement: The data presented in this study are available on request from the corresponding author.

Acknowledgments: The authors would like to thank participants and research assistants for their contribution to this study.

Conflicts of Interest: The authors declare no conflict of interest.

\section{References}

Brown, Ryan P. 2003. Measuring Individual Differences in the Tendency to Forgive: Construct Validity and Links with Depression. Personality and Social Psychology Bulletin 29: 759-71. [CrossRef]

Chen, Ying, Sion Kim Harris, Everett L. Worthington Jr., and Tyler J. VanderWeele. 2019. Religiously or Spiritually-Motivated Forgiveness and Subsequent Health and Well-Being among Young Adults: An Outcome-Wide Analysis. The Journal of Positive Psychology 14: 649-58. [CrossRef]

Davis, Don E., Joshua N. Hook, Daryl R. Van Tongeren, and Everett L. Worthington Jr. 2012. Sanctification of Forgiveness. Psychology of Religion and Spirituality 4: 31-39. [CrossRef]

Davis, Don E., Man Yee Ho, Brandon J. Griffin, Chris Bell, Joshua N. Hook, Daryl R. Van Tongeren, Cirleen DeBlaere, Everett L. Worthington, and Charles J. Westbrook. 2015. Forgiving the Self and Physical and Mental Health Correlates: A Meta-Analytic Review. Journal of Counseling Psychology 62: 329-35. [CrossRef]

Derdaele, Elke, Loren Toussaint, Evalyne Thauvoye, and Jessie Dezutter. 2019. Forgiveness and Late Life Functioning: The Mediating Role of Finding Ego-Integrity. Aging $\mathcal{E}$ Mental Health 23: 238-45. [CrossRef] 
Emmons, Robert A. 2005. Emotion and Religion. In Handbook of Thepsychology of Religion and Spirituality. Edited by Raymond F. Paloutzian and Crystal L. Park. New York: Guilford Press, pp. 235-52.

Enright, Robert, Susan Freedman, and Joanna Rique. 1998. The Psychology of Interpersonal Forgiveness. In Exploring Forgiveness, edited by Robert Enright and Joanna North. Madison: University of Wisconsin, pp. 46-62.

Erikson, Erik. 1959. Identity and the Life Cycle. New York: International University Press.

Exline, Julie J., Ann Marie Yali, and Marci Lobel. 1999. When God Disappoints Difficulty Forgiving God and Its Role in Negative Emotion. Journal of Health Psychology 4: 365-79. [CrossRef]

Fitzgibbons, Richard P. 1986. The Cognitive and Emotive Uses of Forgiveness in the Treatment of Anger. Psychotherapy: Theory, Research, Practice, Training 23: 629-33. [CrossRef]

Frankl, Viktor. 1962. Man's Search for Meaning. Boston: Beacon Press.

Głaz, Stanisław. 2019. The Relationship of Forgiveness and Values with Meaning in Life of Polish Students. Journal of Religion and Health 58: 1886-907. [CrossRef]

Hantman, Shira, and Orna Cohen. 2010. Forgiveness in Late Life. Journal of Gerontological Social Work 53: 613-30. [CrossRef]

Hayes, Andrew F. 2018. Introduction to Mediation, Moderation, and Conditional Process Analysis: A Regression-Based Approach, 2nd ed. New York: The Guilford Press.

Hill, Peter C., and Evonne Edwards. 2013. Measurement in the Psychology of Religiousness and Spirituality: Existing Measures and New Frontiers. In APA Handbook of Psychology, Religion, and Spirituality (Vol 1): Context, Theory, and Research. Edited by Kenneth I. Pargament, Julie J. Exline and James W. Jones. APA Handbooks in Psychology. Washington: American Psychological Association, pp. 51-77.

Hood, Ralph W., Peter C. Hill, and Bernard Spilka. 2009. The Psychology of Religion: An Empirical Approach, 4th ed. New York: Guilford Press.

Huber, S., Marie Allemand, and Odilo W. Huber. 2011. Forgiveness by God and Human Forgivingness: The Centrality of the Religiosity Makes the Difference. Archiv Für Religionspsychologie/Archive for the Psychology of Religion 33: 115-34. [CrossRef]

Huber, Stefan, and Odilo W. Huber. 2012. The Centrality of Religiosity Scale (CRS). Religions 3: 710-24. [CrossRef]

Huber, Stefan. 2007. Are Religious Beliefs Relevant in Daily Life? In Religion Inside and Outside Traditional Institutions. Edited by Heinz Streib. Leiden and Boston: Brill, pp. 211-30.

Huber, Stefan. 2008. Kerndimensionen, Zentralität und Inhalt. Ein Interdisziplinäres Modell der Religiosität. Journal für Psychologie 16: 1-17. [CrossRef]

Kossakowska, Marlena, Piotr Kwiatek, and Tomasz Stefaniak. 2014. Sens w życiu. Polska wersja kwestionariusza MLQ (Meaning in Life Questionnaire). Psychology of Quality of Life 12: 111-31. [CrossRef]

Krause, Neal. 2004. Stressors arising in highly valued roles, meaning in life, and the physical health status of older adults. The Journals of Gerontology Series B: Psychological Sciences and Social Sciences 59: S287-S97.

Krok, Dariusz. 2009. Religijność a Jakość Życia w Perspektywie Mediatorów Psychospołecznych. Opole: Redakcja Wydawnictw Wydziału Teologicznego Uniwersytetu Opolskiego.

Krok, Dariusz. 2014. The Religious Meaning System and Subjective Well-Being. Archive for the Psychology of Religion 36: $253-73$. [CrossRef]

Krok, Dariusz. 2015. The Role of Meaning in Life Within the Relations of Religious Coping and Psychological Well-Being. Journal of Religion and Health 54: 2292-308. [CrossRef]

Laufer, Avital, Yaira Raz-Hamama, Stephen Z. Levine, and Zahava Solomon. 2009. Posttraumatic Growth in Adolescence: The Role of Religiosity, Distress, and Forgiveness. Journal of Social and Clinical Psychology 28: 862-80. [CrossRef]

Lawler-Row, Kathleen A., and Rachel L. Piferi. 2006. The Forgiving Personality: Describing a Life Well Lived? Personality and Individual Differences 41: 1009-20. [CrossRef]

Macaskill, Ann. 2007. Exploring Religious Involvement, Forgiveness, Trust, and Cynicism. Mental Health, Religion \& Culture 10: 203-18. [CrossRef]

Maltby, John, Ann Macaskill, and Liza Day. 2001. Failure to Forgive Self and Others: A Replication and Extension of the Relationship between Forgiveness, Personality, Social Desirability and General Health. Personality and Individual Differences 30: 881-85. [CrossRef]

Martos, Barna Konkol Thege, and Michael F. Steger. 2010. It's Not Only What You Hold, It's How You Hold It: Dimensions of Religiosity and Meaning in Life. Personality and Individual Differences 49: 863-68. [CrossRef]

McCullough, Michael E., C. Garth Bellah, Shelley Dean Kilpatrick, and Judith L. Johnson. 2001. Vengefulness: Relationships with Forgiveness, Rumination, Well-Being, and the Big Five. Personality and Social Psychology Bulletin 27: 601-10. [CrossRef]

McCullough, Michael E., Giacomo Bono, and Lindsey M. Root. 2007. Rumination, Emotion, and Forgiveness: Three Longitudinal Studies. Journal of Personality and Social Psychology 92: 490-505. [CrossRef]

McCullough, Michael E., K. Chris Rachal, Steven J. Sandage, Everett L. Worthington Jr., Susan Wade Brown, and Terry L. Hight. 1998. Interpersonal Forgiving in Close Relationships: II. Theoretical Elaboration and Measurement. Journal of Personality and Social Psychology 75: 1586-603. [CrossRef]

McCullough, Michael E., and Everett L. Worthington Jr. 1999. Religion and the forgiving personality. Journal of Personality 67: 1141-64. [CrossRef] 
McFadden, Susan H. 2013. Old persons, old age, aging, and religion. In Handbook of the Psychology of Religion and Spirituality. Edited by Raymond F. Paloutzian and Crystal L. Park. New York and London: Guilford Publications, pp. 198-212.

Morano, Carmen L., and Denise King. 2005. Religiosity as a Mediator of Caregiver Weil-Being: Does Ethnicity Make a Difference? Journal of Gerontological Social Work 45: 69-84. [CrossRef]

O'Donnell, Maeve B., Christof N. Bentele, Hannah B. Grossman, Yunying Le, Hoon Jang, and Michael F. Steger. 2014. You, Me, and Meaning: An Integrative Review of Connections between Relationships and Meaning in Life. Journal of Psychology in Africa 24: 44-50. [CrossRef]

Park, Crystal L. 2005. Religion as a Meaning-Making Framework in Coping with Life Stress. Journal of Social Issues 61: 707-29. [CrossRef]

Park, Crystal L. 2013. Religion and Meaning. In Handbook of the Psychology of Religion and Spirituality. Edited by Raymond F. Paloutzian and Crystal L. Park. New York: Guilford Press, pp. 357-79.

Peterson, Christopher, and Martin E. P. Seligman. 2004. Character Strengths and Virtues: A Handbook and Classification. Oxford: Oxford University Press, vol. 1.

Rye, Mark S., Kenneth I. Pargament, M. Amir Ali, Guy L. Beck, Elliot N. Dorff, Charles Hallisey, Vasudha Narayanan, and James G. Williams. 2000. Religious Perspectives on Forgiveness. In Forgiveness: Theory, Research, and Practice. Edited by Michael E. McCullough, Kenneth I. Pargament and Carl E. Thoresen. New York: Guilford, pp. 17-40.

Steger, Michael F. 2009. Meaning in Life. In Oxford Handbook of Positive Psychology. Edited by Shane J. Lopez and Charles R. Snyder. Oxford: Oxford University Press, pp. 679-87.

Steger, Michael F., Patricia Frazier, Shigehiro Oishi, and Matthew Kaler. 2006. The Meaning in Life Questionnaire: Assessing the Presence of and Search for Meaning in Life. Journal of Counseling Psychology 53: 80-93. [CrossRef]

Steger, Michael F., Todd B. Kashdan, Brandon A. Sullivan, and Danielle Lorentz. 2008. Understanding the search for meaning in life: Personality, cognitive style, and the dynamic between seeking and experiencing meaning. Journal of Personality 76: 199-228. [CrossRef]

Thompson, Laura Yamhure, Charles R. Snyder, Lesa Hoffman, Scott T. Michael, Heather N. Rasmussen, Laura S. Billings, Laura Heinze, Jason E. Neufeld, Hal S. Shorey, Jessica C. Roberts, and et al. 2005. Dispositional Forgiveness of Self, Others, and Situations. Journal of Personality 73: 313-60. [CrossRef]

Tornstam, Lars. 2005. Gerotranscendence: A Developmental Theory of Positive Aging. New York: Springer Publishing Company.

Toussaint, Loren L., Ani Kalayjian, and Daria Diakonova-Curtis. 2017. Forgiveness Makes Sense: Forgiving Others Enhances the Salutary Associations of Meaning-Making with Traumatic Stress Symptoms. Peace and Conflict: Journal of Peace Psychology 23: 85-88. [CrossRef]

Toussaint, Loren L., Everett L. Worthington Jr., and David R. Williams. 2015. Forgiveness and Health: Scientific Evidence and Theories Relating Forgiveness to Better Health. Berlin: Springer.

Van Dyke, Cydney J., and Maurice J. Elias. 2007. How Forgiveness, Purpose, and Religiosity Are Related to the Mental Health and Well-Being of Youth: A Review of the Literature. Mental Health, Religion \& Culture 10: 395-415. [CrossRef]

Van Tongeren, Daryl R., Jeffrey D. Green, Joshua N. Hook, Don E. Davis, Jody L. Davis, and Marciana Ramos. 2015. Forgiveness Increases Meaning in Life. Social Psychological and Personality Science 6: 47-55. [CrossRef]

Witvliet, Charlotte van Oyen, Scott R. Hinze, and Everett L. Worthington. 2008. Unresolved Injustice: Christian Religious Commitment, Forgiveness, Revenge, and Cardiovas- Cular Responding. Journal of Psychology and Christianity 27: 110-119.

Worthington, Everett L., Jr. 2005. Handbook of Forgiveness. New York and London: Routledge.

Zarzycka, Beata. 2019. Predictors and Mediating Role of Forgiveness in the Relationship between Religious Struggle and Mental Health. Polskie Forum Psychologiczne 24: 93-116.

Zarzycka, Beata, Rafał P. Bartczuk, and Radosław Rybarski. 2020. Centrality of Religiosity Scale in Polish Research: A Curvilinear Mechanism that Explains the Categories of Centrality of Religiosity. Religions 11: 64. [CrossRef] 